\title{
Rapidly evolving treatment paradigm and considerations for sequencing therapies in metastatic prostate cancer-a narrative review
}

\author{
Smitha Sagaram, Arpit Rao \\ University of Minnesota, Masonic Cancer Center, Minneapolis, MN, USA \\ Contributions: (I) Conception and design: All authors; (II) Administrative support: A Rao; (III) Provision of study materials or patients: None; (IV) \\ Collection and assembly of data: All authors; (V) Data analysis and interpretation: All authors; (VI) Manuscript writing: All authors. (VII) Final \\ approval of manuscript: All authors. \\ Correspondence to: Arpit Rao, MD. 420 Delaware St. SE, MMC 480, Minneapolis, MN 55455, USA. Email: raoa@umn.edu.
}

\begin{abstract}
The treatment landscape of metastatic prostate cancer (mPCa) has evolved considerably over the past 15 years with approvals of targeted therapies such as poly-ADP-ribose polymerase inhibitors (PARPi) in castration-resistant [metastatic castration-resistant prostate cancer (mCRPC)] setting and novel antiandrogens and docetaxel in hormone-sensitive [metastatic hormone-sensitive prostate cancer (mHSPC)] setting. A number of promising clinical trials are now evaluating therapeutic combinations rooted in an improving understanding of tumor biology. Despite a plethora of effective treatment options, decisions regarding choice of therapy remain challenging due to the lack of head-to-head trials and a substantial overlap in selection criteria used in these trials. We summarize the data from key trials that led to approval of commonly used mPCa therapies and provides an easy-to-use clinical decision-making framework that incorporates patient-specific and disease-specific factors to aid selection of the optimal therapy. We outline the evolving use-cases for biomarker-guided treatment selection and our approach to incorporating these therapies in clinical practice. Finally, we highlight the rapidly growing pipeline of therapies that are in advanced stages of clinical development, such as combinations of novel antiandrogen and PARPi, vascular endothelial growth factor (VEGF) inhibitor and immunotherapy, as well as prostate specific membrane antigen (PSMA)-targeted therapies, many of which are poised to transform the landscape in the coming decade.
\end{abstract}

Keywords: Metastatic castration-resistant prostate cancer (mCRPC); poly-ADP-ribose polymerase inhibitor
(PARPi); targeted therapy; microsatellite instability-high (MSI-high); lutetium prostate-specific membrane antigen
(lutetium PSMA)

Submitted Aug 17, 2020. Accepted for publication Dec 08, 2020.

doi: $10.21037 /$ tau-20-1383

View this article at: http://dx.doi.org/10.21037/tau-20-1383

\section{Introduction}

Prostate cancer is the second common malignancy in men globally accounting for approximately 1.2 million new cases and 350,000 deaths in 2018 (1). In the U.S., although prostate cancer death rate has declined by $52 \%$, from a peak of 39.3 (per 100,000) in 1993 to a low of 18.8 in 2017, it still remains the second leading cause of cancer related mortality in males despite advances made in understanding the underlying molecular mechanisms in the last two decades (2). Resistance to androgen deprivation therapy (termed castration-resistance) and disease progression with a prostate-specific antigen (PSA) rise, radiographic progression; and/or development of new or worsening clinical-related symptoms or complications eventually occur in all patients, and metastatic prostate cancer remains a lethal disease with 5 -year relative survival rate of $30.5 \%$ (3). 
The treatment paradigm of metastatic castrationresistant prostate cancer (mCRPC) shifted in 2004 with the U.S. Food and Drug Administration (F.D.A.) approval of docetaxel chemotherapy based on overall survival (OS) benefit (4). Prior to the approval of docetaxel, therapies such as mitoxantrone were approved on the basis of improvement in palliative endpoints in mCRPC, but none had shown an OS benefit. Since 2004, several agents have been approved in mCRPC including novel anti-androgens (NAA) such as abiraterone and enzalutamide; radium-223, cabazitaxel and sipuleucel-T. Furthermore, NAA and docetaxel are now approved in metastatic hormone-sensitive prostate cancer (mHSPC). Despite the availability of these new therapies, selection of optimal treatment remains a challenge as there are limited head-to-head comparison trials.

In this review article, we summarize the data from key trials that led to F.D.A. approval of commonly-used therapies and provide an easy-to-use clinical decisionmaking framework that incorporates patient-specific and disease-specific factors to aid selection of the optimal therapy. Ongoing clinical development of promising therapies that could shift the paradigm once again will also be discussed. We present the following article in accordance with the Narrative Review reporting checklist (available at http://dx.doi.org/10.21037/tau-20-1383).

\section{Methods}

U.S. F.D.A database was searched to identify therapies approved for use in mHSPC and mCRPC between January 1996 and July 2020. All trials that contributed data to the F.D.A. indication and referenced in the F.D.A. label were included. A Medline search was performed using the following keywords-metastatic prostate cancer, phase 1, phase 2, phase 3 , clinical trial, trial, systematic review. Additional pertinent articles were identified after discussions with experts in the field and based on the authors' personal experiences from participation in several literature reviews on the subject.

\section{Discussion}

\section{Landscape of therapeutic agents approved in advanced prostate cancer}

An overview of the agents approved by the F.D.A. for use in mCRPC and non-mCRPC and corresponding key clinical trials is summarized in Table 1. Agents approved by the
F.D.A. for use in mHSPC are summarized in Table 2. For the remainder of this article, we will focus on treatment options pertinent to the mCRPC disease setting.

\section{Picking the optimal first-line mCRPC therapy -an abundance of riches}

Two NAAs (abiraterone and enzalutamide) are approved in the pre- and post-docetaxel settings and widely used for the treatment of mCRPC. Abiraterone inhibits $17 \alpha$-hydroxylase/C17,20-lyase, enzymes necessary for androgen synthesis intratumorally and in the testicular, prostate, and adrenal tissues (29). Enzalutamide is an androgen receptor (AR) antagonist that competitively inhibits androgen binding to $A R$, and its nuclear translocation and interaction with DNA (30). In first-line mCRPC, abiraterone and enzalutamide have comparable efficacy with median radiographic progression-free survival (rPFS) of approximately 15 months and median OS of approximately 32 months (Table 1). Thus, the choice is often guided by adverse effect profiles of these drugs, physician comfort, and payor-specific factors such as drug coverage and copays. However, there's data to suggest that sequencing could be an additional consideration as discussed below.

Clinical trajectory at presentation should be considered before choosing NAA as the first-line therapy. Pivotal NAA clinical trials-COU-AA-302 (12) and PREVAIL (15)—only included patients with asymptomatic or mildly symptomatic disease, and excluded those needing opiate analgesia or radiation for prostate cancer prior to enrollment. COUAA-302 further excluded patients with visceral metastatic disease. In our clinical experience, patients who would have been excluded from these trials usually benefit from NAA therapy, but responses tend to be less durable. Hence, our preferred first-line approach for patients with rapidly progressing $\mathrm{mCRPC}$, or $\mathrm{mCRPC}$ with adverse prognostic features (such as hepatic metastases) is docetaxel or a clinical trial when possible.

Other first-line options for mCRPC patients include radium-223 for those with bony metastases without visceral metastatic disease, and sipuleucel-T for asymptomatic/minimally symptomatic patients with typically slow-growing disease. Radium-223 is a targeted alpha emitting radiotherapeutic and the first radiopharmaceutical to demonstrate an OS advantage in metastatic prostate cancer (31). Sipuleucel-T is an autologous cellular immunotherapy designed to induce an immune response targeted against prostatic acid phosphatase (PAP), an antigen 
Table 1 FDA approval timeline of agents used in advanced prostate cancer and corresponding key clinical trials

\begin{tabular}{|c|c|c|c|c|c|}
\hline FDA approval & $\begin{array}{l}\text { Investigational arm } \\
\text { (control arm) }\end{array}$ & Approval indication & Trial & Primary endpoint(s) & Results \\
\hline \multirow[t]{2}{*}{1996} & $\begin{array}{l}\text { Mitoxantrone }+ \\
\text { prednisone (steroid) }\end{array}$ & $\begin{array}{l}\text { M1 CRPC, treatment of } \\
\text { pain }\end{array}$ & $\begin{array}{l}\text { CALGB } 9182 \text { (5), } \\
\text { CCI-NOV22 }\end{array}$ & $\begin{array}{l}\text { Median duration of } \\
\text { primary and overall } \\
\text { palliative response }\end{array}$ & $\begin{array}{l}\text { Median duration of primary } \\
\text { palliative response: } 7.6 \text { vs. } \\
2.1 \text { months }(P=0.0009)\end{array}$ \\
\hline & & & & & $\begin{array}{l}\text { Median duration of overall } \\
\text { palliative response: } 5.6 \text { vs. } \\
1.9 \text { months }(P=0.0004)\end{array}$ \\
\hline 2004 & $\begin{array}{l}\text { Docetaxel + prednisone } \\
\text { (mitoxantrone }+ \\
\text { prednisone) }\end{array}$ & M1 CRPC & TAX327 (6) & Os & $\begin{array}{l}18.9 \text { vs. } 16.5 \text { months } \\
\text { (HR 0.79; } \\
95 \% \text { Cl: } 0.62-0.94 ; \\
P=0.009 \text { ) }\end{array}$ \\
\hline 2010 & Sipuleucel-T (placebo) & $\begin{array}{l}\text { M1 CRPC, autologous } \\
\text { cellular immunotherapy for } \\
\text { asymptomatic or minimally } \\
\text { symptomatic }\end{array}$ & $\operatorname{IMPACT}(7,8)$ & os & $\begin{array}{l}25.8 \text { vs. } 21.7 \text { months } \\
\text { (HR 0.78; } \\
95 \% \text { Cl: } 0.61-0.98 ; P=0.03 \text { ) }\end{array}$ \\
\hline 2010 & $\begin{array}{l}\text { Cabazitaxel + prednisone } \\
\text { (mitoxantrone }+ \\
\text { prednisone) }\end{array}$ & M1 CRPC, post-docetaxel & TROPIC (9) & os & $\begin{array}{l}15.1 \text { vs. } 12.7 \text { months } \\
\text { (HR 0.70; } \\
95 \% \mathrm{Cl}: 0.59-0.83 \text {; } \\
\mathrm{P}<0.0001)\end{array}$ \\
\hline 2011 & $\begin{array}{l}\text { Abiraterone + prednisone } \\
\text { (placebo + prednisone) }\end{array}$ & M1 CRPC, post-docetaxel & COU-AA-301 (10) & os & $\begin{array}{l}14.8 \text { vs. } 10.9 \text { months } \\
\text { (HR 0.65; } \\
95 \% \mathrm{Cl}: 0.54-0.77 \text {; } \\
\mathrm{P}<0.001 \text { ) }\end{array}$ \\
\hline 2012 & Enzalutamide (placebo) & M1 CRPC, post-docetaxel & AFFIRM (11) & OS & $\begin{array}{l}18.4 \text { vs. } 13.6 \text { months } \\
\text { (HR 0.63; } \\
95 \% \mathrm{Cl}: 0.53-0.75 \\
\mathrm{P}<0.001 \text { ) }\end{array}$ \\
\hline 2013 & $\begin{array}{l}\text { Radium-223 (best SOC or } \\
\text { placebo) }\end{array}$ & $\begin{array}{l}\text { M1 CRPC pre-and } \\
\text { post-docetaxel for } \\
\text { symptomatic bone-only } \\
\text { metastases }\end{array}$ & ALSYMPCA $(13,14)$ & OS & $\begin{array}{l}14.9 \text { vs. } 11.3 \text { months } \\
\text { (HR 0.70; } \\
95 \% \mathrm{Cl}: 0.55-0.88 \\
\mathrm{P}=0.002 \text { ) }\end{array}$ \\
\hline 2014 & Enzalutamide (placebo) & M1 CRPC pre-docetaxel & PREVAIL (15) & OS & $\begin{array}{l}32.4 \text { vs. } 30.4 \text { (HR 0.71; } \\
95 \% \mathrm{Cl}: 0.60-0.84 \\
\mathrm{P}<0.001)\end{array}$ \\
\hline 2017 & $\begin{array}{l}\text { Cabazitaxel } 20 \text { mg/m² } \\
\text { q3 weeks (C20) } \\
\text { (cabazitaxel } 25 \text { mg/m² } \\
\text { every } 3 \text { weeks; C25) }\end{array}$ & M1 CRPC post docetaxel & PROSELICA (16) & $\begin{array}{l}\text { (Non-inferiority of) } \\
\text { OS }\end{array}$ & $\begin{array}{l}\text { Non-inferiority met, with } \\
\text { HR } 1.024 \text { and one-sided } \\
98.89 \% \text { upper } \mathrm{Cl} \text { being } \\
1.184\end{array}$ \\
\hline 2018 & Enzalutamide (placebo) & MO CRPC & PROSPER (17) & $\begin{array}{l}\text { Metastasis-free } \\
\text { survival }\end{array}$ & $\begin{array}{l}36.6 \text { vs. } 14.7 \text { months } \\
\text { (HR 0.29; } \\
95 \% \mathrm{Cl}: 0.24-0.35 \text {; } \\
\mathrm{P}<0.001 \text { ) }\end{array}$ \\
\hline
\end{tabular}

Table 1 (continued) 
Table 1 (continued)

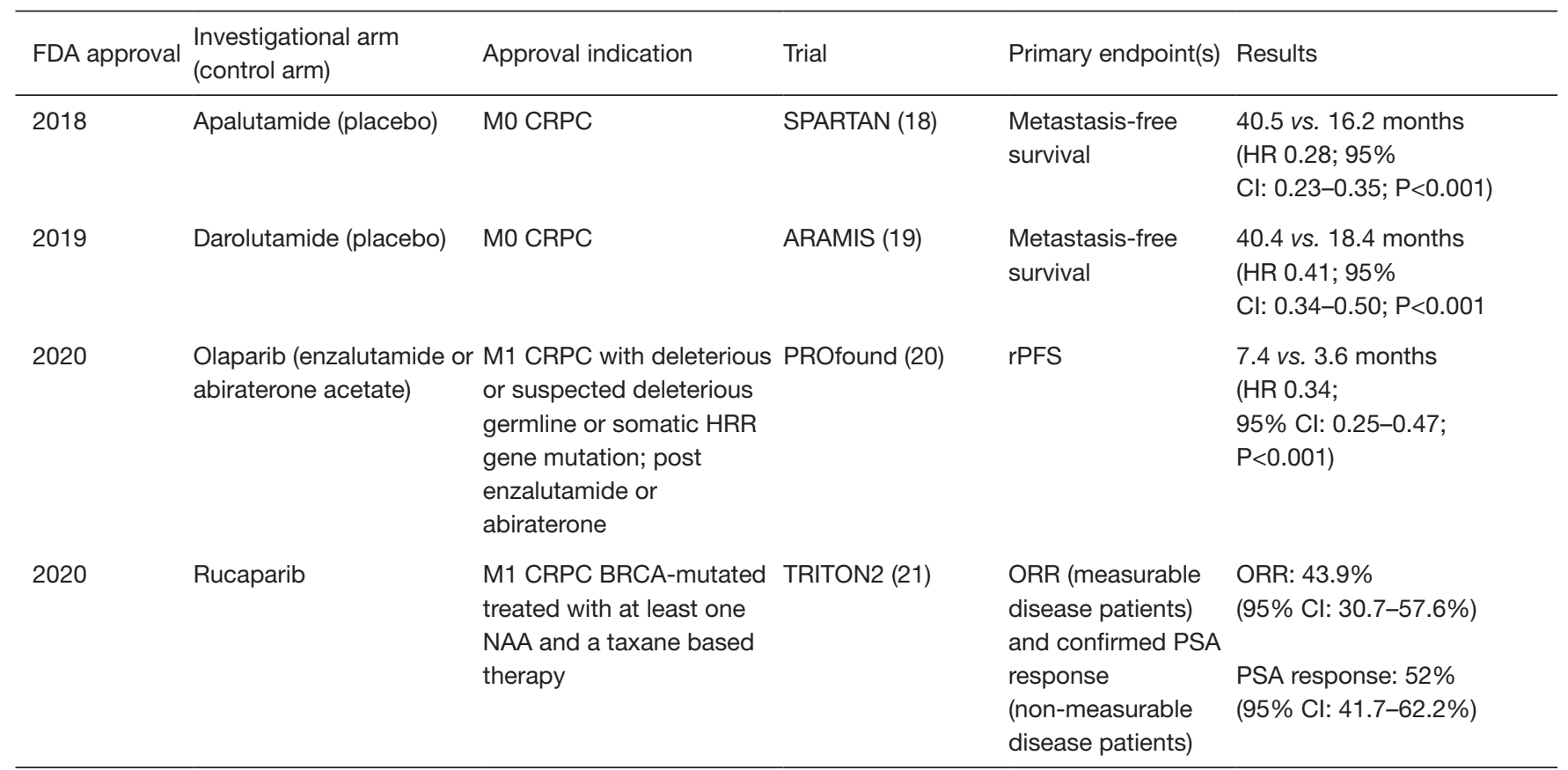

M1, metastatic; M0, non-metastatic; CRPC, castration-resistant prostate cancer; OS, overall survival; PFS, progression-free survival; HR, hazard ratio; $\mathrm{Cl}$, confidence interval; rPFS, radiographic progression-free survival; ORR, overall response rate; PSA, prostate-specific antigen.

expressed in most prostate cancers. Both radium-223 and sipuleucel-T have shown OS benefit in key clinical trials (Table 1) however, there are logistical considerations that must be made prior to placing patients on these treatments such as the access to nuclear medicine theranostic capabilities for radium-223 and plasmapheresis for sipuleucel-T.

A number of approaches have been investigated to improve upon monotherapy responses in first-line mCRPC. A031201 was a pivotal randomized phase 3 trial that evaluated enzalutamide and abiraterone $v s$. enzalutamide alone in patients with mCRPC (32). The trial failed to show an OS benefit (33.6 vs. 32.7 months; $\mathrm{P}=0.19$ ). PSA declines were comparable in the two arms as well but there was a trend towards improved rPFS with enzalutamide/ abiraterone when compared to enzalutamide alone (25.2 vs. 20.7 months; $\mathrm{P}=0.02$ ). The adverse event (specifically, fatigue, hypertension, atrial fibrillation) rates, however, were considerably higher in the combination group. Based on this data, combination of anti-androgen therapies should not be used for patients with mCRPC. Currently, there are no approved combination therapies for first-line mCRPC.

Several clinical trials are currently evaluating combinations of AR signaling inhibitors with other agents. One promising approach is to combine AR antagonist with a poly-ADPribose polymerase (PARP) inhibitor based on the longrecognized pre-clinical observation that co-inhibition of AR signaling and PARP induces synthetic lethality in DNA-damage response proficient (e.g., non-BRCA mutant) prostate cancer cell lines (33). CASPAR is a randomized, placebo-controlled phase 3 trial evaluating the combination of enzalutamide and rucaparib $v s$. enzalutamide alone in mCRPC patients with or without DNA-damage response gene aberrations (ClinicalTrials.gov ID: NCT04455750).

In parallel, there is an effort to evaluate other antiandrogens that appear to have a better safety profile than the current standard-of-care (SOC) therapies. One such trial is ARACOG, a randomized, open-label phase 2 trial comparing cognitive outcomes in patients treated with treated with darolutamide or enzalutamide for non-CRPC and mCRPC (ClinicalTrials.gov ID: NCT04335682).

\section{Sequencing considerations in second and subsequent lines of therapies}

Data suggests that sequencing enzalutamide after abiraterone may provide the greatest clinical benefit (34). A 
Table 2 FDA approval timeline of agents used in hormone-sensitive prostate cancer and corresponding key clinical trials

\begin{tabular}{|c|c|c|c|c|c|}
\hline FDA approval & $\begin{array}{l}\text { Investigational arm } \\
\text { (control arm) }\end{array}$ & $\begin{array}{l}\text { Approval } \\
\text { indication }\end{array}$ & Trial & $\begin{array}{l}\text { Primary } \\
\text { endpoint(s) }\end{array}$ & Results \\
\hline $\begin{array}{l}\text { Not FDA } \\
\text { approved }^{*}\end{array}$ & $\begin{array}{l}\text { Docetaxel + ADT } \\
\text { (ADT alone) }\end{array}$ & $\begin{array}{l}\text { High-volume } \\
\text { M1 HSPC }\end{array}$ & $\begin{array}{l}\text { CHAARTED (22); } \\
\text { GETUG-AFU-15 (23); } \\
\text { STAMPEDE (24) }\end{array}$ & OS & $\begin{array}{l}\text { CHAARTED: } 57.6 \text { vs. } 44.0 \text { months } \\
\text { (HR 0.61; 95\% Cl: } 0.47-0.80 ; \mathrm{P}<0.001) \\
\text { GETUG-AFU-15: } 58.9 \text { vs. } 54.2 \text { months } \\
\text { (HR 1.01, 95\% Cl: } 0.75-1.36) \\
\text { STAMPEDE: } 81 \text { vs. } 71 \text { months } \\
(0.78,0.66-0.93 ; \mathrm{P}=0.006)\end{array}$ \\
\hline 2018 & $\begin{array}{l}\text { Abiraterone + ADT + } \\
\text { prednisolone } \\
\text { (ADT alone) }\end{array}$ & $\begin{array}{l}\text { High-risk M1 } \\
\text { HSPC }\end{array}$ & $\begin{array}{l}\text { STAMPEDE (24); } \\
\text { LATITUDE (25) }\end{array}$ & OS; OS and rPF & $\begin{array}{l}\text { STAMPEDE: } 3 \text {-year survival of } 83 \% \text { vs. } 76 \% \\
\text { (HR 0.63; } 95 \% \mathrm{Cl} \text { : } 0.52-0.76 ; \mathrm{P}<0.001 \text { ) } \\
\text { LATITUDE: median OS not reached vs. } \\
34.7 \text { months } \\
\text { (HR 0.62; } 95 \% \mathrm{Cl}: 0.51-0.76 ; \mathrm{P}<0.001 \text { ) } \\
\text { Median rPFS } 33.0 \text { vs. } 14.8 \text { months } \\
\text { (HR } 0.47 ; 95 \% \mathrm{Cl}: 0.39-0.55 ; \mathrm{P}<0.001 \text { ) }\end{array}$ \\
\hline 2019 & $\begin{array}{l}\text { Enzalutamide + ADT } \\
\text { (placebo + ADT) }\end{array}$ & M1 HSPC & $\begin{array}{l}\text { ARCHES (26); } \\
\text { ENZAMET (27) }\end{array}$ & rPFS & $\begin{array}{l}\text { Median not reached vs. } 19.0 \text { months } \\
\text { (HR 0.39; 95\% Cl: } 0.30-0.50 ; \mathrm{P}<0.001)\end{array}$ \\
\hline 2019 & $\begin{array}{l}\text { Apalutamide + ADT } \\
\text { (placebo + ADT) }\end{array}$ & M1 HSPC & TITAN (28) & rPFS and OS & $\begin{array}{l}\text { Median rPFS: Not reached vs. } 22.1 \text { months } \\
\text { (HR 0.48; 95\% Cl: 0.39-0.60; } \mathrm{P}<0.001 \text { ) } \\
\text { 2-year OS: } 82.4 \% \text { vs. } 73.5 \% \\
\text { (HR 0.67; 95\% Cl: } 0.51-0.89 ; \mathrm{P}=0.005 \text { ) }\end{array}$ \\
\hline
\end{tabular}

*, not FDA approved but widely used in this setting based on demonstration of efficacy. M1, metastatic; HSPC, hormone-sensitive prostate cancer; ADT, androgen deprivation therapy; HR, hazard ratio; Cl, confidence interval; rPFS, radiographic progression-free survival; OS, overall survival.

randomized, phase 2, crossover trial assigned 202 mCRPC patients to either (I) abiraterone acetate plus prednisone until PSA progression followed by per-protocol crossover to enzalutamide or (II) enzalutamide until PSA progression followed by per-protocol cross over to abiraterone (34). Time to second PSA progression was longer in the abiraterone-first group than the enzalutamide-first group [median 19.3 vs. 15.2 months; hazard ratio (HR) 0.66, $95 \%$ CI: $0.45-0.97, \mathrm{P}=0.036$ ], at a median follow-up of 22.8 months. Additionally, a greater proportion of patients had PSA response to second-line enzalutamide therapy (36\%) than abiraterone therapy $\left(4 \% ; \chi^{2} \mathrm{P}<0.0001\right)$. These data, while not definitive for an improvement in OS, are thought provoking for several reasons including the mechanisms that lead to abiraterone and enzalutamide resistance.

Retrospective studies have similarly found limited activity of abiraterone after enzalutamide failure in chemotherapynaive patients. In one such study, PSA decline of $\geq 50 \%$ was noted in only $7 \%$ of patients (35). All else being equal, our preferred approach is to give abiraterone acetate followed by enzalutamide in first-line mCRPC setting.

Patients who progress quickly with NAA therapy may represent an aggressive disease phenotype who may benefit from receiving chemotherapy earlier rather than a second NAA therapy. This is supported by the recently reported data from the CARD trial, which was a randomized, openlabel study of cabazitaxel $v s$. abiraterone or enzalutamide in mCRPC patients previously treated with three or more cycles of docetaxel and progressing within 12 months on either abiraterone or enzalutamide (given pre- or postdocetaxel) (36). Regimen was cabazitaxel $25 \mathrm{mg}$ per square meter of body-surface area given intravenously every 3 weeks with prednisone daily and granulocyte colony-stimulating factor until progression. Cabazitaxel outperformed NAA with a median rPFS of 8.0 months compared with 3.7 months for NAA (HR 0.54; $95 \%$ CI: $0.40-0.73 ; \mathrm{P}<0.001)$ and median OS of 13.6 vs. 11.0 months for NAA (HR for death, 0.64; 95\% CI: 0.46-0.89; $\mathrm{P}=0.008$ ). PSA response was higher in cabazitaxel group (35.7\%) compared with NAA group $(13.5 \%$; $\mathrm{P}<0.001)$. Cabazitaxel 
is our preferred option for patients who meet CARD trial criteria and are otherwise fit to receive this therapy.

\section{Status of biomarker-based (targeted) therapies in mCRPC}

\section{AR splice variant (AR-V7)}

AR-V7 has been extensively investigated as a potential predictive biomarker for treatment selection in mCRPC (37). In a cross-sectional cohort study of $161 \mathrm{mCRPC}$ patients, patients with AR-V7 negative circulating tumor cells (CTCs) (as determined by Oncotype DX AR-V7 Nuclear Detect test) (38), superior OS was seen with taxanes compared to NAA when AR-V7-positive CTCs were detected pre-therapy (HR 0.24; 95\% CI: 0.10-0.57; $\mathrm{P}=0.035$ ). In the PROPHECY trial, AR-V7 detection (as determined by both Hopkins modifiedAdna Test CTC AR-V7 mRNA assay and the Epic Sciences CTC nuclear AR-V7 protein assay) was found to be associated with a shorter PFS (3.1 vs. 7.3 months for AR-V7 positive vs. AR-V7 negative groups as determined by the Hopkins test and 3.1 vs. 6 months for AR-V7 positive vs. negative groups as determined by the Epic test) and OS (11.5 vs. 25.5 months for AR-V7 positive $v s$. negative groups as determined by the Hopkins test and 8.4 vs. 25.5 months for AR-V7 positive vs. negative groups as determined by the Epic test) in mCRPC patients treated with abiraterone or enzalutamide (39). A key limitation prohibiting widespread adoption of AR-V7 in clinical practice is that second NAA therapy is typically well tolerated and AR-V7 testing itself can be expensive, associated with logistical challenges (may take a few weeks to result), and may not ultimately rule out a treatment response. We do not pursue routine $\mathrm{AR}-\mathrm{V} 7$ testing in our clinical practice outside of the context of a clinical trial.

\section{Microsatellite instability-high (MSI-H)/mismatch repair-deficient (dMMR) status}

Approximately $3-8 \%$ of prostate cancer patients have MSI-H/dMMR tumors $(40,41)$. Due to high tumor neoantigen burden, patients with $\mathrm{d} M M \mathrm{R}$ tumors exhibit durable responses to immune checkpoint inhibitor treatment regardless of site of origin. Pembrolizumab was granted accelerated approval by the FDA for the treatment of patients with unresectable or metastatic, MSI-H or dMMR solid tumors that have progressed following prior treatment and who have no satisfactory alternative treatment options (42). In our practice, this is the preferred treatment option for any patient with MSI-H/dMMR after progression on at least one SOC therapy. Data from larger prospective mCRPC trials are lacking to inform the length and durability of responses in this patient population.

Homologous recombination repair (HRR) aberrations Two PARP inhibitors, rucaparib and olaparib received FDA approval in May 2020 for use in mCRPC harboring selected HRR aberrations after progression on at least one NAA therapy (olaparib) and at least one NAA and one chemotherapy (rucaparib) $(43,44)$. PROfound trial is a randomized, open-label, phase 3 trial of patients with HRR-mutated mCRPC progressing on abiraterone or enzalutamide that were randomized to olaparib or physician's choice of SOC therapy (20). Patients were assigned to one of two cohorts based on the HRR gene alteration. Cohort A consisted of mCRPC patients with BRCA1, BRCA2, or ATM alteration regardless of co-occurring alteration in any other HRR gene and cohort $\mathrm{B}$ consisted of mCRPC patients with alterations in any of the other 12 HRR genes. Median rPFS was significantly longer in the olaparib group than in the SOC group (7.4 vs. 3.6 months; HR 0.34; 95\% CI: $0.25-0.47$; $\mathrm{P}<0.001$ ). The confirmed objective response rate was $33 \%$ in the olaparib group and $2 \%$ in the SOC group (odds ratio 20.86; 95\% CI: 4.18-379.18; $\mathrm{P}<0.001)$. The median time to pain progression was also significantly longer in the olaparib group (HR, 0.44; 95\% CI: 0.22-0.91; $\mathrm{P}=0.02$ ). An interim analysis for OS at $38 \%$ data maturity showed that median OS was longer in the olaparib group than in the SOC group (18.5 vs. 15.1 months; HR 0.64; 95\% CI: 0.43-0.97; $\mathrm{P}=0.02)$. Of note, $81 \%$ of patients in the SOC group had crossed over to receive olaparib treatment at the time of this analysis.

TRITON2 is an ongoing, multi-center, single-arm clinical trial of rucaparib in men with HRR-mutated (germline and/or somatic) mCRPC who have previously received at least one novel antihormonal agent and taxanebased chemotherapy (21). As of Feb 2019, 190 patients had received rucaparib $600 \mathrm{mg}$ orally twice daily. Confirmed overall response rate (ORR) was 43.9\% (25/57; $95 \%$ CI: $30.7-57.6 \%)$ in patients with a BRCA1/2 alteration and RECIST-defined measurable disease at baseline. ORR was comparable in patients with a germline BRCA1/2 alteration (38.1\%; 95\% CI: 18.1-61.6\%) and somatic BRCA1/2 alteration (48.6\%; 95\% CI: $31.4-66.0 \%)$. The median duration of response was not reached but the range was 1.7 to 24+ months.

Currently, the use of these agents is contingent upon the presence of aberrations in the HRR gene as identified on a commercial assay. Patients must have received at least 
one line of prior therapy with abiraterone or enzalutamide (olaparib and rucaparib), and one line of therapy with taxane chemotherapy (rucaparib). Completion of ongoing clinical trials as discussed in the following section may broaden the use of these agents in other prostate cancer disease states. Another hurdle in the use of predictive biomarkers to guide PARP inhibitor use is inadequate tissue sampling. For example, about $30 \%$ patients in the PROfound trial and $17 \%$ patients in TOPARB-B trial could not be molecularly screened due to insufficient tissue or poor tissue quality (45). The CASPAR (A031902; Clinicaltrials.gov ID: NCT04455750) trial will investigate the concordance between circulating tumor (ct)-DNA based "liquid biopsy" and archival tissue based conventional biopsy to evaluate whether the former can overcome this key limitation and make molecularly-targeted therapies a viable option for a larger proportion of mCRPC patients.

\section{Emerging options in mCRPC}

\section{Combination therapy with PARP inhibition}

PARP proteins play a key role in many cellular processes, making PARP inhibitors an attractive partner for several therapies (46). Data from a phase $1 \mathrm{~b} / 2$ study that evaluated a combination of a PARP inhibitor (talazoparib) with an immune checkpoint inhibitor (avelumab) in patients with advanced solid tumors including mCRPC showed preliminary antitumor activity and a manageable safety profile (47). Upcoming combination trials include PARP inhibitor with chemotherapy such as docetaxel/carboplatin (NCT03442556) or immunotherapy such as nivolumab, pembrolizumab, durvalumab (NCT03338790, NCT072478, NCT03810105, NCT02861573, NCT03431350) or radiopharmaceuticals lutetium-177-labeled SMA-617, radium-223 (NCT03874884, NCT03317392, NCT03076203).

A phase 2 clinical trial evaluated the efficacy of olaparib plus abiraterone in patients with $\mathrm{mCRPC}$ regardless of HRR mutation status and demonstrated clinical efficacy benefit in these patients (48). An NCI/Alliance-sponsored randomized, placebo-controlled phase 3 trial of rucaparib and enzalutamide in untreated mCRPC [CASPAR; A031902 (NCT04455750)] is expected to launch soon and several others are currently ongoing [PROpel (NCT03732820), MAGNITUDE (NCT03748641), TALAPRO-2 (NCT03395197)].

\section{Vascular endothelial growth factor (VEGF) inhibition}

VEGF is well-known as a stimulator of angiogenesis and is highly expressed in solid tumor cells including prostate cancer. Cabozantinib is an oral, small molecule, tyrosine kinase inhibitor (TKI) that targets VEGFR2, AXL, c-MET and RET. Cabozantinib showed no survival benefit in two key mCRPC phase 3 trials, COMET-1 (49) and COMET-2 (50) when compared to prednisone and prednisone plus mitoxantrone, respectively, in post-docetaxel mCRPC patients. Recently, a phase 1b trial (COSMIC-021) (51) evaluated combination therapy of cabozantinib plus immune checkpoint inhibitor, atezolizumab in mCRPC who progressed on enzalutamide and/or abiraterone treatment, or chemotherapy. Objective response rate in this study was $32 \%$ and disease control rate (objective response plus stable disease) was $80 \%$ at a median follow-up of 12.6 months. Median duration of response for all responding patients was 8.3 months. Furthermore, grade 3 and 4 adverse events were minimal in the study. CONTACT-02, a randomized phase 3 trial of this combination $v$ s. second-line NAA in mCRPC, was recently launched to further investigate this early efficacy signal (NCT04446117). If successful, this would represent a resurgence of cabozantinib in the mCRPC setting.

\section{Immunotherapy}

Beyond dMMR mCRPC described above, the role of immune checkpoint inhibitors in MCRPC is not well established and several early monotherapy trials have yielded low and disappointing response rates. Two phase 3 trials that evaluated ipilimumab monotherapy in mCRPC did not demonstrate an OS benefit $(52,53)$. Data from recent combination studies have also been disappointing. In the phase 2 KEYNOTE-199 study of docetaxel-treated mCRPC patients, pembrolizumab monotherapy resulted in ORR of only $5 \%$ in patients with programmed cell death ligand 1 (PD-L1)-positive disease (54). In the phase 3 IMbassador250 study that evaluated addition of atezolizumab, an immune check-point inhibitor to enzalutamide in mCRPC patients whose disease progressed on abiraterone and were ineligible for or refused a taxane regimen showed that the combination failed to improve OS when compared with enzalutamide alone (55).

Treatment combinations that result in immune activation through a multitude of pathways are being investigated. One such approach is evaluating a combination of abemaciclib and atezolizumab in biomarker unselected mCRPC as well as CDK12-mutant mCRPC (56).

\section{Prostate specific membrane antigen (PSMA) targeted therapy}

PSMA is a glycoprotein that is overexpressed on prostate 
cancer cells. Lutetium-177-PSMA is a radiolabeled small molecule that binds with high affinity to PSMA and delivers therapeutic beta-emitting radiation to tumor sites. Preliminary results from the randomized phase 2 TheraP trial showed that PSA response (PSA decline $\geq 50 \%$ ) was significantly higher in the lutetium-177-labeled PSMA-617 arm $(66 \%)$ compared with cabazitaxel $(37 \%$; $\mathrm{P}<0.0001)$ in men with mCRPC that had progressed on docetaxel (57).

Chimeric antigen receptor $\mathrm{T}$ (CAR-T) cell therapy is being used successfully to treat hematological malignancies such as lymphomas and leukemias. CAR-T technology is currently being evaluated in prostate cancer expressing PSMA and/or prostate stem cell antigen (PSCA). Selected phase 1 of this promising approach to immunotherapy in mCRPC include NCT04227275, NCT04053062, NCT04249947, NCT03013712, NCT03873805, NCT02744287, and NCT03089203.

\section{Conclusions}

Treatment paradigm of metastatic prostate cancer has evolved in the past 15 years. Approval of PARP inhibitor monotherapy has opened the door for targeted therapies in MCRPC and a growing number of promising clinical trials are evaluating a myriad of therapeutic combinations rooted in an improving understanding of tumor biology. The key challenges for the coming decade are to improve upon the efficacy of NAA monotherapy, to utilize synergistic approaches to improve responses to immunotherapy and to establish non-invasive assays that allow serial interrogation of tumor biology.

\section{Acknowledgments}

Funding: None.

\section{Footnote}

Provenance and Peer Review: This article was commissioned by the Guest Editors (Badrinath R Konety, Daniel W. Lin) for the series "Current and Future Topics on Prostate Cancer" published in Translational Andrology and Urology. The article has undergone external peer review.

Reporting Checklist: The authors have completed the NARRATIVE REVIEW reporting checklist. Available at http://dx.doi.org/10.21037/tau-20-1383

Conflicts of Interest: All authors have completed the ICMJE uniform disclosure form (available at http://dx.doi. org/10.21037/tau-20-1383). The series "Current and Future Topics on Prostate Cancer" was commissioned by the editorial office without any funding or sponsorship. Dr. AR reports grants from Clovis Oncology, grants from Eli Lilly and Company, other from Bayer Inc., outside the submitted work. SS has no other conflicts of interest to declare.

Ethical Statement: The authors are accountable for all aspects of the work in ensuring that questions related to the accuracy or integrity of any part of the work are appropriately investigated and resolved.

Open Access Statement: This is an Open Access article distributed in accordance with the Creative Commons Attribution-NonCommercial-NoDerivs 4.0 International License (CC BY-NC-ND 4.0), which permits the noncommercial replication and distribution of the article with the strict proviso that no changes or edits are made and the original work is properly cited (including links to both the formal publication through the relevant DOI and the license). See: https://creativecommons.org/licenses/by-nc-nd/4.0/.

\section{References}

1. Bray F, Ferlay J, Soerjomataram I, et al. Global cancer statistics 2018: GLOBOCAN estimates of incidence and mortality worldwide for 36 cancers in 185 countries. CA Cancer J Clin 2018;68:394-424. Erratum in: CA Cancer J Clin. 2020 Jul;70(4):313. doi: 10.3322/caac.21609. Epub 2020 Apr 6.

2. Cancer Facts \& Figures 2020. Am Cancer Society, 2020.

3. NCI. Cancer Stat Facts: Prostate Cancer [Internet]. [cited 2020 Jun 24]. Available online: https://seer.cancer.gov/ statfacts/html/prost.html

4. Tannock IF, de Wit R, Berry WR, et al. Docetaxel plus prednisone or mitoxantrone plus prednisone for advanced prostate cancer. N Engl J Med 2004;351:1502-12.

5. Novantrone mitoxantrone [package insert]. Rockland, MA: EMD Serono, Inc., 2010.

6. Dagher R, Li N, Abraham S, et al. Approval summary: Docetaxel in combination with prednisone for the treatment of androgen-independent hormone-refractory prostate cancer. Clin Cancer Res 2004;10:8147-51.

7. Kantoff PW, Higano CS, Shore ND, et al. Sipuleucel-T immunotherapy for castration-resistant prostate cancer. $\mathrm{N}$ Engl J Med 2010;363:411-22. 
8. Provenge (sipeleucel-T) [package insert]. Seattle, WA: Dendreon Corporation, 2010;

9. de Bono JS, Oudard S, Ozguroglu M, et al. Prednisone plus cabazitaxel or mitoxantrone for metastatic castrationresistant prostate cancer progressing after docetaxel treatment: a randomised open-label trial. Lancet 2010;376:1147-54.

10. de Bono JS, Logothetis CJ, Molina A, et al. Abiraterone and increased survival in metastatic prostate cancer. $\mathrm{N}$ Engl J Med 2011;364:1995-2005.

11. Scher HI, Fizazi K, Saad F, et al. Increased survival with enzalutamide in prostate cancer after chemotherapy. $\mathrm{N}$ Engl J Med 2012;367:1187-97.

12. Ryan CJ, Smith MR, Fizazi K, et al. Abiraterone acetate plus prednisone versus placebo plus prednisone in chemotherapy-naive men with metastatic castrationresistant prostate cancer (COU-AA-302): final overall survival analysis of a randomised, double-blind, placebocontrolled phase 3 study. Lancet Oncol 2015;16:152-60.

13. Kluetz PG, Pierce W, Maher VE, et al. Radium Ra 223 Dichloride Injection: U.S. Food and Drug Administration Drug Approval Summary. Clin Cancer Res 2014;20:9-14.

14. Parker C, Nilsson S, Heinrich D, et al. Alpha Emitter Radium-223 and Survival in Metastatic Prostate Cancer. N Engl J Med 2013;369:213-23.

15. Beer TM, Armstrong AJ, Rathkopf DE, et al. Enzalutamide in metastatic prostate cancer before chemotherapy. N Engl J Med 2014;371:424-33.

16. Eisenberger M, Hardy-Bessard AC, Kim CS, et al. Phase III Study Comparing a Reduced Dose of Cabazitaxel (20 $\mathrm{mg} / \mathrm{m} 2$ ) and the Currently Approved Dose $(25 \mathrm{mg} / \mathrm{m} 2)$ in Postdocetaxel Patients With Metastatic CastrationResistant Prostate Cancer-PROSELICA. J Clin Oncol 2017;35:3198-206.

17. Hussain M, Fizazi K, Saad F, et al. Enzalutamide in Men with Nonmetastatic, Castration-Resistant Prostate Cancer. N Engl J Med 2018;378:2465-74.

18. Smith MR, Saad F, Chowdhury S, et al. Apalutamide Treatment and Metastasis-free Survival in Prostate Cancer. N Engl J Med 2018;378:1408-18.

19. Fizazi K, Shore N, Tammela TL, et al. Darolutamide in Nonmetastatic, Castration-Resistant Prostate Cancer. N Engl J Med 2019;380:1235-46.

20. de Bono J, Mateo J, Fizazi K, et al. Olaparib for Metastatic Castration-Resistant Prostate Cancer. N Engl J Med 2020;382:2091-102.

21. Abida W, Campbell D, Patnaik A, et al. Preliminary results from the TRITON2 study of rucaparib in patients (pts) with DNA damage repair (DDR)-deficient metastatic castration-resistant prostate cancer (mCRPC): Updated analyses. Ann Oncol 2019;30:V327-V328.

22. Sweeney CJ, Chen YH, Carducci M, et al. Chemohormonal Therapy in Metastatic HormoneSensitive Prostate Cancer. N Engl J Med 2015;373:737-46.

23. Gravis G, Fizazi K, Joly F, et al. Androgen-deprivation therapy alone or with docetaxel in non-castrate metastatic prostate cancer (GETUG-AFU 15): a randomised, openlabel, phase 3 trial. Lancet Oncol 2013;14:149-58.

24. James ND, de Bono JS, Spears MR, et al. Abiraterone for Prostate Cancer Not Previously Treated with Hormone Therapy. N Engl J Med 2017;377:338-51.

25. Fizazi K, Tran N, Fein L, et al. Abiraterone plus Prednisone in Metastatic, Castration-Sensitive Prostate Cancer. N Engl J Med 2017;377:352-60.

26. Armstrong AJ, Szmulewitz RZ, Petrylak DP, et al. ARCHES: A Randomized, Phase III Study of Androgen Deprivation Therapy With Enzalutamide or Placebo in Men With Metastatic Hormone-Sensitive Prostate Cancer. J Clin Oncol 2019;37:2974-86.

27. Davis ID, Martin AJ, Stockler MR, et al. Enzalutamide with Standard First-Line Therapy in Metastatic Prostate Cancer. N Engl J Med 2019;381:121-31.

28. Chi KN, Agarwal N, Bjartell A, et al. Apalutamide for Metastatic, Castration-Sensitive Prostate Cancer. N Engl J Med 2019;381:13-24.

29. Zytiga Package Insert, Janssen Biotech 2012, Revised 2015. Accessed on July 28, 2020. Available online: https://www.accessdata.fda.gov/drugsatfda_docs/ label/2015/202379s016lbl.pdf

30. Xtandi Product Label. Northbrook, IL: Astellas Pharrma, 2015. Accessed on July 28, 2020. https://www.accessdata. fda.gov/drugsatfda_docs/label/2015/203415s007lbl.pdf

31. Smith M, Parker C, Saad F, et al. Addition of radium-223 to abiraterone acetate and prednisone or prednisolone in patients with castration-resistant prostate cancer and bone metastases (ERA 223): a randomised, doubleblind, placebo-controlled, phase 3 trial. Lancet Oncol 2019;20:408-19. Erratum in: Lancet Oncol. 2019 Oct;20(10):e559. doi: 10.1016/S1470-2045(19)30587-X. Epub 2019 Sep 30.

32. Morris MJ, Heller G, Bryce AH, et al. Alliance A031201: A phase III trial of enzalutamide (ENZ) versus enzalutamide, abiraterone, and prednisone (ENZ/AAP) for metastatic castration resistant prostate cancer (mCRPC). J Clin Oncol 2019;37:abstr 5008. 
33. Schiewer MJ, Knudsen KE. Linking DNA Damage and Hormone Signaling Pathways in Cancer. Trends Endocrinol Metab 2016;27:216-25.

34. Khalaf DJ, Annala M, Taavitsainen S, et al. Optimal sequencing of enzalutamide and abiraterone acetate plus prednisone in metastatic castration-resistant prostate cancer: a multicentre, randomised, open-label, phase 2, crossover trial. Lancet Oncol 2019;20:1730-9.

35. Yamada Y, Matsubara N, Tabata KI, et al. Abiraterone acetate after progression with enzalutamide in chemotherapy-naïve patients with metastatic castrationresistant prostate cancer: a multi-center retrospective analysis. BMC Res Notes 2016;9:471.

36. de Wit R, de Bono J, Sternberg CN, et al. Cabazitaxel versus Abiraterone or Enzalutamide in Metastatic Prostate Cancer. N Engl J Med 2019;381:2506-18.

37. Bastos DA, Antonarakis ES. AR-V7 and treatment selection in advanced prostate cancer: are we there yet? Precis Cancer Med 2018;1:13.

38. Scher HI, Lu D, Schreiber NA, et al. Association of ARV7 on Circulating Tumor Cells as a Treatment-Specific Biomarker With Outcomes and Survival in CastrationResistant Prostate Cancer. JAMA Oncol 2016;2:1441-9. Erratum in: JAMA Oncol. 2016 Nov 1;2(11):1511. doi: 10.1001/jamaoncol.2016.4680.

39. Armstrong AJ, Halabi S, Luo J, et al. The PROPHECY trial: Multicenter prospective trial of circulating tumor cell (CTC) AR-V7 detection in men with mCRPC receiving abiraterone (A) or enzalutamide (E). J Clin Oncol 2018;36:abstr 5004.

40. Abida W, Cheng ML, Armenia J, et al. Analysis of the Prevalence of Microsatellite Instability in Prostate Cancer and Response to Immune Checkpoint Blockade. JAMA Oncol 2019;5:471-8.

41. Rodrigues DN, Rescigno P, Liu D, et al. Immunogenomic analyses associate immunological alterations with mismatch repair defects in prostate cancer. J Clin Invest 2018;128:5185.

42. Keytruda Product Label. Whitehouse Station, NJ: Merck \& Co. Revised April 2019. [Internet]. [cited 2020 Jul 30]. Available online: https://www.accessdata.fda.gov/ drugsatfda_docs/label/2019/125514Orig1s054lbl.pdf

43. U.S. Food and Drug Administration. Full prescribing information for Lynparza (olaparib). [Internet]. [cited 2020 Jul 25]. Available online: https://www.accessdata.fda.gov/ drugsatfda_docs/label/2020/208558s013lbl.pdf

44. U.S. Food and Drug Administration. Full prescribing information for Rubraca (rucaparib). [Internet]. [cited
2020 Jul 25]. Available online: https://www.accessdata.fda. gov/drugsatfda_docs/label/2020/209115s004lbl.pdf

45. Gillessen S, Bristow RG. The tip of the iceberg: predicting PARP inhibitor efficacy in prostate cancer. Lancet Oncol 2020;21:17-9.

46. Rao A, Ryan C. PARP Inhibitors - A Breakthrough in Targeted Therapies for Prostate Cancer [Internet]. UroToday. 2020 [cited 2020 Jul 24]. Available online: https://www.urotoday.com/library-resources/mcrpctreatment/122336-parp-inhibitors-a-breakthrough-intargeted-therapies-for-prostate-cancer.html

47. Yap TA, Konstantinopoulos P, Telli ML, et al. AVELIN PARP Medley, a phase 1b/2 study of avelumab plus talazoparib: Results from advanced breast cancer cohorts. Cancer Res 2020;80:abstr P1-19-03.

48. Clarke N, Wiechno P, Alekseev B, et al. Olaparib combined with abiraterone in patients with metastatic castration-resistant prostate cancer: a randomised, doubleblind, placebo-controlled, phase 2 trial. Lancet Oncol 2018;19:975-86.

49. Smith M, De Bono J, Sternberg C, et al. Phase III Study of Cabozantinib in Previously Treated Metastatic CastrationResistant Prostate Cancer: COMET-1. J Clin Oncol 2016;34:3005-13.

50. Basch EM, Scholz M, de Bono JS, et al. Cabozantinib Versus Mitoxantrone-prednisone in Symptomatic Metastatic Castration-resistant Prostate Cancer: A Randomized Phase 3 Trial with a Primary Pain Endpoint. Eur Urol 2019;75:929-37.

51. Agarwal N, Loriot Y, McGregor BA, et al. Cabozantinib in combination with atezolizumab in patients with metastatic castration-resistant prostate cancer: Results of cohort 6 of the COSMIC-021 study. J Clin Oncol 2020;38:abstr 5564.

52. Kwon ED, Drake CG, Scher HI, et al. Ipilimumab versus placebo after radiotherapy in patients with metastatic castration-resistant prostate cancer that had progressed after docetaxel chemotherapy (CA184-043): a multicentre, randomised, double-blind, phase 3 trial. Lancet Oncol 2014;15:700-12.

53. Beer TM, Kwon ED, Drake CG, et al. Randomized, Double-Blind, Phase III Trial of Ipilimumab Versus Placebo in Asymptomatic or Minimally Symptomatic Patients With Metastatic Chemotherapy-Naive Castration-Resistant Prostate Cancer. J Clin Oncol 2017;35:40-7.

54. Antonarakis ES, Piulats JM, Gross-Goupil M, et al. Pembrolizumab for Treatment-Refractory Metastatic Castration-Resistant Prostate Cancer: Multicohort, Open- 
Label Phase II KEYNOTE-199 Study. J Clin Oncol 2020;38:395-405.

55. Sweeney CJ, Gillessen S, Rathkopf D, et al. IMbassador250: A phase III trial comparing atezolizumab with enzalutamide vs enzalutamide alone in patients with metastatic castration-resistant prostate cancer (mCRPC). AACR Annual Meeting 2020; April 27-28, 2020 and June 22-24, 2020; Philadelphia, PA. Cancer Res 2020;80:abstr CT014.

Cite this article as: Sagaram S, Rao A. Rapidly evolving treatment paradigm and considerations for sequencing therapies in metastatic prostate cancer-a narrative review. Transl Androl Urol 2021;10(7):3188-3198. doi: 10.21037/tau-20-1383
56. NCT03706365. Clinical Trials.gov. Accessed July 30, 2020. Available online: https://clinicaltrials.gov/ct2/show/ NCT03706365 term $=$ arpit+rao $\&$ draw $=2 \&$ rank $=2$

57. Hofman MS, Emmett L, Sandhu SK et al. TheraP: A randomized phase III trial of 177Lu-PSMA-617 theranostic versus cabazitaxel in metastatic castrationresistant prostate cancer progressing after docetaxel: Initial results (ANZUP protocol 1603). J Clin Oncol 2020;38:abstr 5500. 